\title{
Time of day of taking immunosuppressive agents after renal transplantation: a possible influence on graft survival
}

\author{
M S KNAPP, N P BYROM, R POWNALL, P MAYOR
}

\section{Summary and conclusions}

Large-amplitude circadian rhythms in immune responses and the known variations in the effects of glucocorticoids with the time of day of administration suggest that immunosuppressive regimens may need to take this variable into account. In two similar groups of patients with renal transplants functioning satisfactorily after three months subsequent graft failure developed in $66 \%$ of those taking all immunosuppressives in the evening, compared with only $22 \%$ of those taking immunosuppressives twice daily $(p<0.05)$. A survey of other transplant units showed that one unit with outstanding results - graft survival at three years $82 \%$ - had a unique policy of morning-only administration of immunosuppressives.

Doctors need to consider more carefully the time of drug administration when prescribing, as it may be possible to obtain better results with less toxicity.

\section{Introduction}

The time of day at which drugs are taken may influence their effectiveness or toxicity, but there are few examples of these variations in pharmacology influencing the way doctors prescribe treatment. Several aspects of glucocorticoid activity are altered by the time of administration, including adrenopituitary suppression, ${ }^{1}$ weight gain, ${ }^{2}$ the pattern of urine excretion, ${ }^{3}$ and the effect on delayed hypersensitivity-type immune responses. ${ }^{45}$ Adrenopituitary suppression is minimal when glucocorticoids are taken close to the time of waking, ${ }^{16}$ but many physicians do not consider this when prescribing. Morning-only administration from the onset of glucocorticoid treatment was an important recommendation of those who initially proposed alternate-day treatment to reduce side effects ${ }^{6}$; this regimen was most often recommended to improve growth and accelerate delayed sexual maturity in children but was also used by some doctors treating adults. Some who use this approach do not instruct their patients that all corticosteroids should be taken close to the time of waking, and some use divided doses.

Out of 12 papers describing alternate-day treatment after transplantation only one commented precisely on the time of administration, four suggested morning dosing, and of the remainder, either frequency or time, or both, were not stated. Out of 14 recent papers relating to long-term use of alternate-day steroids for the treatment of other conditions, such as asthma and rheumatoid arthritis, eight suggested single dosing at 07000800 and two morning dosing, but in four the time and frequency were unspecified.

It is uncertain whether any of the effects of azathioprine, the other immunosuppressive agent used by nearly all renal transplant units, vary with the time of administration. Several cytotoxic drugs, which are also immunosuppressive, do show large variations in activity and toxicity with different times of

Renal Unit, City Hospital, Nottingham NG5 1 PB

M S KNAPP, MD, FRCP, consultant physician

N P BYROM, MB, MRCP, senior registrar

R POWNALL, PHD, research scientist

P MAYOR, MB, house officer (now senior house officer, Walsgrove Hospital, Coventry) administration." When immunosuppressive drugs are given $\frac{\overline{\bar{m}}}{\overrightarrow{7}}$ may be important and might be a critical factor when used to $\varrho$ prevent or treat allograft rejection.

In $1973 \mathrm{McGeown}$ conducted a survey to determine the doses $\vec{\circ}$ of immunosuppressives prescribed by different transplant units in Britain. ${ }^{8} \mathrm{~A}$ similar survey was recently carried out in the United $\vec{\omega}$ States. ${ }^{910}$ These surveys showed wide variations in the total $\partial$ dose used but did not consider the time of day when patients 3 were instructed to take medication or the frequency with which iv the drugs were administered. Information about the time of $\stackrel{\infty}{\rightarrow}$ administration is not usually provided by those describing immunosuppressive regimens in papers or textbooks.

In recent papers describing gradual withdrawal of prednisolone after renal transplantation and discussing the possible $\omega_{\infty}$ influence of adrenopituitary function on graft $\operatorname{loss}^{1112}$ no infor- $N$ mation was given on the time of day that the patients had taken prednisolone other than in the period immediately before predni- $N$ solone was withdrawn and adrenopituitary response evaluated. $Z$

We conducted a survey to see whether the frequency and time of dosing in British transplant units varied between units. In $\frac{\Phi}{3}$ Nottingham, where the policy on timing of treatment had not $\frac{\mathbb{D}}{8}$ been consistent, patients were questioned on when they took their medication, and this information was considered in relation $\vec{\varphi}$ to the development of allograft rejection.

\section{Methods}

National survey-A one-page questionnaire was sent to the 24 응 British transplant units, of whom 15 replied. The information requested included the dose of immunosuppressive drugs used, the frequency of administration, and, if standard times of administration were recommended, the details of these times.

Nottingham survey-This considered patients who had received a renal graft more than three months before and whose graft had functioned for at least six months. Patients, or the relatives of those who had died, were questioned about the frequency and timing of drug intake after transplantation. Information was available on 36 out of $\frac{\sigma}{3}$ 100 patients who had received transplants; in the remainder either irreversible rejection had occurred before three months or reliable o information was no longer available in the detail required. The clinical course of the patients was plotted graphically using the reciprocal 음 of the plasma creatinine concentration. These plots, especially when $\mathrm{N}$ viewed in retrospect, permitted accurate definition of the onset of $\sigma$ acute or chronic episodes of decreased renal function (figure) ${ }^{13} \frac{\mathrm{D}}{\mathrm{O}}$ In the absence of other explanations these were considered to be due to allograft rejection. One patient, who had been taking her drugs twice $N$ daily after discharge from hospital, changed to once-daily dosing (all N in the morning); this was followed within a few days by increased $\sigma$ plasma creatinine concentrations (figure), associated with histological evidence of glomerulonephritis but with features of rejection. This patient was excluded from analysis because she had changed the timing $\mathbb{D}$ of treatment just before the deterioration in renal function and because ?+ the reasons for graft failure were uncertain.

\section{Results}

NATIONAL SURVEY

The many variations in the initial dose of immunosuppressive drug given at the time of operation, the dose of drugs given in the posttransplantation period, and the extra doses given to treat rejection $\rightleftharpoons$ episodes were recorded. Variations in the frequency and timing of maintenance doses of prednisolone and azathioprine, which were the 
only regular immunosuppressives prescribed by all units, were considerable (table I). Most units prescribed prednisolone in divided doses and azathioprine in a single dose. Only one unit, in Belfast, instructed patients that both drugs were to be taken as a single morning dose at 1000 , except during rejection episodes. Most units did not give specific instructions to patients about the timing of administration, but only about the total dose and, sometimes, the frequency of administration.

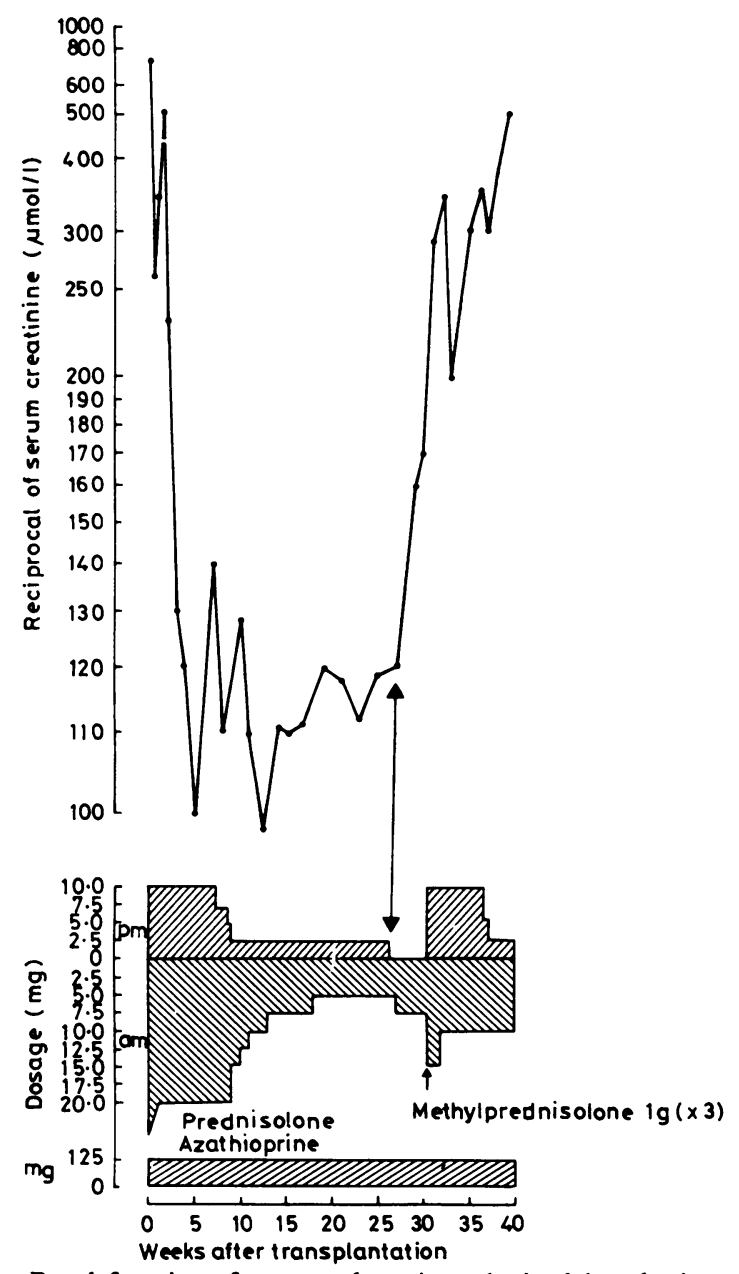

Renal function after transplantation, obtained by plotting reciprocal of serum creatinine concentration, showing abrupt deterioration when patient changed from taking prednisolone twice daily to once daily.

Conversion: SI to traditional units-Creatinine: $1 \mu \mathrm{mol} / 1 \approx$

$11.3 \mu \mathrm{g} / 100 \mathrm{ml}$.

TABLE I-Patterns of administration of prednisolone and azathioprine in transplant units in Britain

\begin{tabular}{|c|c|c|c|c|c|c|c|}
\hline & \multicolumn{7}{|c|}{ Frequency and timing } \\
\hline & \multicolumn{2}{|c|}{ Once daily } & \multirow{2}{*}{$\begin{array}{l}\text { Twice daily } \\
\text { (am and pm) }\end{array}$} & \multirow{2}{*}{$\begin{array}{c}\text { Thrice } \\
\text { daily }\end{array}$} & \multirow{2}{*}{$\begin{array}{c}\text { Alternate } \\
\text { days }\end{array}$} & \multirow{2}{*}{ Variable } & \multirow[b]{2}{*}{ Unstated } \\
\hline & am & pm & & & & & \\
\hline $\begin{array}{l}\text { Prednisolone } \\
\text { Azathioprine }\end{array}$ & $\begin{array}{l}2 \\
1\end{array}$ & $\begin{array}{l}1 \\
5\end{array}$ & $\begin{array}{l}6 \\
2\end{array}$ & $\begin{array}{l}1 \\
2\end{array}$ & 1 & $\begin{array}{l}3 \\
3\end{array}$ & $\begin{array}{l}1 \\
2\end{array}$ \\
\hline
\end{tabular}

Only the Belfast unit, which had
prednisolone and azathioprine.

\section{NOTTINGHAM SURVEY}

Patients receiving a renal transplant in Nottingham were initially prescribed drugs according to a protocol used at the Glasgow Western Infirmary, ${ }^{14}$ which stated the total daily dose but not the distribution throughout the day or the timing. All 35 patients took some or all of their azathioprine between 1800 and 2200 . Of these, five divided it into morning and evening doses. Sixteen patients took all their prednisolone once daily in the evening, five took it all in the morning, and 14 split the total dose into morning and evening doses, the morning dose usually being the larger. All had taken the larger doses of prednisolone used in hospital in three or four divided doses and had continued this at home initially, but later most patients decreased the frequency. When asked how they decided when to take tablets they usually stated that they initially copied the hospital but then changed "to evening doses only, because this was when the hospital 'phoned instructions after a clinic visit"; "on the advice of a doctor or a nurse"; "because an equal amount morning and night seemed logical"; and "for convenience." At least one patient may have changed to evening doses after hearing a local radio broadcast about research that showed that immune responses may be more vigorous at night.

In the 16 patients taking both azathioprine and prednisolone in evening-only doses chronic progressive loss of graft function occurred in 10 , leading to total loss of function in seven, and late acute rejection reversible with treatment occurred in one. Only five of the 16 taking evening-only doses had therefore sustained uneventfully the satisfactory function they all had had three months after transplantation.

Nineteen patients were taking divided doses of one or both immunosuppressives. Of these, most of whom were taking twice-daily (morning and evening) prednisolone, $15(79 \%)$ did not develop chronic rejection during follow-up and only two lost all kidney function. No patients took all of their immunosuppressive treatment in the morning. The group of patients taking evening-only doses and the group taking divided doses were similar in many respects (table II). The average periods of observation after transplantation were $29 \cdot 1$ and 29.5 months respectively. Only the age of patients in the two groups was significantly different (39.7 years in the evening-only group $v 27.3$ years in the twice-daily group, $\mathrm{p}<0.02$ ), but this is not known to have an influence on late allograft rejection. Those taking evening-only doses appeared more likely to experience chronic rejection $(\mathrm{p}<0.05)$.

\section{Discussion}

Large variations occur in the success rates of transplant units which are clearly shown by analyses of results collected from units in Britain. ${ }^{1516}$ At one unit $82 \%$ of cadaver kidney grafts function for more than three months, and 75\% for 36 months, ${ }^{16} 17$ compared with under $20 \%$ for three months at other units. ${ }^{15}$ Other units show intermediate results with a median of $55 \%$ of grafts functioning at three months and $38 \%$ at 36 months. At some units loss of graft function after three months of useful function is unusual. ${ }^{17}$ In others over $20 \%$ of grafts functioning at three months fail in the next three years. It is clearly important to establish why some units are more successful than others. Many factors have been considered, but none have explained the observed differences. Variations in prescribing policy may be relevant, and the timing of dosing may be important in preventing rejection episodes.

Results of a survey in $1973^{\circ}$ suggested that lower doses of glucocorticoid might be as effective, or more effective, than higher doses. The Belfast unit used only $20 \mathrm{mg}$ prednisolone daily except during rejection and achieved better results than all the other British units, and it was suggested that this might be due to the low doses used. ${ }^{17}$ This hypothesis, however, was not supported by the results of a trial conducted in Oxford. ${ }^{18}$ In this $30 \mathrm{mg} /$ day prednisolone was used, reducing at two months to $20 \mathrm{mg} / \mathrm{day}$, although large doses of methylprednisolone were given during rejection and as prophylaxis on the sixth, seventh, and eighth days after transplantation. Results obtained were no better than those in a matched group treated with more conventional and larger doses of corticosteroid, and did not reproduce the results obtained in Belfast. The most obvious difference between the two regimens was that intravenous methylprednisolone was given in Oxford, rather than the oral high-dose prednisolone used when treating rejection in Belfast. These methods of treating rejection had given comparable results in earlier trials, ${ }^{10} 20$ and the reason why the Oxford results did not reproduce those obtained in Belfast remains unexplained. A less obvious difference was that in Belfast all immunosuppression, except during rejection, was given at 1000 , but in Oxford both azathioprine and prednisolone were given in divided doses in the morning and evening. Our survey indicates that the regimen used in Belfast 
is unusual, and possibly unique, in the timing of the treatment. Could this be as important or more important than some of the other variables?

Single daily dosing was chosen by the Belfast unit to encourage compliance, and the time of administration was selected to suit the organisation of the unit (M G McGeown, personal communication). Whether the drugs might be more effective when given in this way was not considered. Giving prednisolone at 1000 will cause little or no pituitary suppression, and endogenous adrenal secretion of cortisone should continue. ${ }^{21}$ This continued production of cortisol may be important, especially as the high output just before and just after waking coincides with the time when immune responses may be at their most vigorous ${ }^{22}$ and it appeared to develop late rejection more often $(10 / 16)$ than those taking morning and evening doses (4/19), but in both groups late rejection occurred more often than in Belfast, where only morning doses were given. Analyses did not identify any im- $\propto$ portant differences between the two groups, though the patients $c$ were not randomly allocated as would occur in a controlled trial. $\overrightarrow{\vec{D}}$ When comparing the Nottingham results with those obtained in $\frac{9}{0}$ Belfast it must be appreciated that there were other differences $\frac{0}{0}$ in the details of the protocols used in the two centres besides the times of administration.

In one Nottingham patient loss of graft function followed abruptly a change to morning-only treatment (figure) but adrenopituitary suppression was probably operating in this patient, $\overrightarrow{0}$

TABLE II-Group comparison of 35 renal transplant recipients

\begin{tabular}{|c|c|c|c|c|c|c|}
\hline & \multicolumn{6}{|c|}{ Timing of immunosuppressive treatment } \\
\hline & \multicolumn{3}{|c|}{ Evening only $(n=16)$} & \multicolumn{3}{|c|}{$\begin{array}{l}\text { Divided doses in } \\
\text { morning and evening }(n=19)\end{array}$} \\
\hline & Mean & Median & Range & Mean & Median & Range \\
\hline \multirow{5}{*}{$\begin{array}{l}\text { Sex: } \\
\text { Male } \\
\text { Female } \\
\text { Age (years) at transplantation } \\
\text { Donor: } \\
\text { Cadaver } \\
\text { Living relation } \\
\text { Time (months) on dialysis } \\
\text { HLA (A and B loci) matches } \\
\text { No of recipients who received blood } \\
\text { transfusion before transplantation } \\
\text { Units of blood received/patient } \\
\text { Dose of azathioprine (mg//g/day) } \ddagger \\
\text { Dose of prednisolone (mg/kg/day) } \ddagger \\
\text { White cell count ( } \times 10 \% / 1) \neq \\
\text { Minimum serum creatinine ( } \mu \text { mol/1) } \\
\text { No of acute rejection episodes during } \\
\text { first three months } \\
\text { No with chronic rejection } \\
\text { No with stable function (other than } \\
\text { reversible late acute rejection) } \\
\text { Duration of follow-up (months) }\end{array}$} & $\begin{array}{c}7 \\
9 \\
39 \cdot 7\end{array}$ & $44 \cdot 2$ & $15 \cdot 5-57 \cdot 8$ & $\begin{array}{c}14 \\
5 \\
27 \cdot 3\end{array}$ & $22 \cdot 75$ & $9 \cdot 58-53 \cdot 17^{*}$ \\
\hline & $\begin{array}{c}16 \\
0 \\
6 \cdot 8 \\
1.3\end{array}$ & $\begin{array}{l}2 \cdot 0 \\
1.0\end{array}$ & $\begin{array}{l}0-49 \\
0-3\end{array}$ & $\begin{array}{c}17 \\
2 \\
10.6 \\
1.5\end{array}$ & $\begin{array}{l}4 \cdot 0 \\
1 \cdot 0\end{array}$ & $\begin{array}{l}0-96 \\
0-3\end{array}$ \\
\hline & $\begin{array}{c}13 \\
2.9 \\
1.93 \\
0.162 \\
6.8 \\
118 \cdot 1\end{array}$ & $\begin{array}{c}3.0 \\
1.95 \\
0.136 \\
116.5\end{array}$ & $\begin{array}{c}0-6 \\
1 \cdot 1-3 \cdot 0 \\
0 \cdot 1-0 \cdot 37 \\
4 \cdot 3-11 \cdot 3 \\
60-186\end{array}$ & $\begin{array}{c}13 \\
3.6 \\
1.64 \\
0.177 \\
6.7 \\
118.7\end{array}$ & $\begin{array}{c}3.0 \\
1.38 \\
0.143 \\
100 \cdot 0\end{array}$ & $\begin{array}{c}0-16 \\
0 \cdot 3-3 \cdot 5 \\
0 \cdot 07-0 \cdot 47 \\
4 \cdot 7-10 \cdot 0 \\
70-280\end{array}$ \\
\hline & $2 \cdot 4$ & $2 \cdot 5$ & $0-4$ & $\begin{array}{l}2 \cdot 0 \\
4 \dagger\end{array}$ & $2 \cdot 0$ & $0-5$ \\
\hline & $\begin{array}{c}6 \\
29 \cdot 1\end{array}$ & $24 \cdot 0$ & $8-66$ & $\begin{array}{l}15 t \\
29 \cdot 5\end{array}$ & $17 \cdot 0$ & $9-69$ \\
\hline
\end{tabular}

will often be a long time since corticosteroids and azathioprine were last administered. In our unit calculations to estimate the time of onset of rejection suggest that this is most likely to occur at night. ${ }^{23} \mathrm{We}$ also showed in the laboratory that the immunosuppressive effect of methylprednisolone is prolonged when given close to the transition from sleep to activity. ${ }^{45}$ Alternatively, giving prednisolone at 1000 avoids pituitary-adrenal suppression and permits normal endogenous cortisol release, resulting in both exogenous and endogenous steroid being available for immunosuppression. The unsuppressed endogenous activity thus supplements the exogenous dose, with some of it being available late in the day and early in the morning.

In at least one steroid-responsive illness, minimal-change nephrotic syndrome, relapse has been linked with the period of hypoadrenalism after conventional thrice-daily corticosteroid treatment, ${ }^{24}$ and relapses in this condition might perhaps be reduced by treatment timed to avoid adrenopituitary suppression. This observation provides some support for the hypothesis that endogenous cortisone production may be important in preventing unwanted manifestations of immune responses. We are unaware of studies into whether the effects of azathioprine may be influenced by the time of administration but would not be surprised if this were so. Azathioprine may prevent rejection of allografts by inhibiting the function or the multiplication of cells critical to the immune response, and most cells show largeamplitude circadian rhythms in their rates of mitoses and functional activity. ${ }^{25}$ We showed large variations in the in-vivo cellmediated immune responses of both rats $^{2627}$ and man ${ }^{22}$ elicited with oxazolone and tuberculin respectively but have not yet completed pharmacological studies using Azathioprine similar to those reported by us with glucocorticoids.

The Nottingham patients with functioning grafts at three months and taking evening-only doses of immunosuppressives who had previously taken divided doses for some months, so $\frac{\circ}{3}$ that morning-only doses of prednisolone might have been critical and caused the deterioration. In one Belfast patient loss? of function was observed after the patient changed from morning to evening dosing (M G McGeown, personal communication) but the temporal relation between the change in timing and lost function was not as close as in the Nottingham patient.

Many variables may influence the outcome after renal transplantation, and evaluating these different factors is difficult. $\frac{3}{3}$ The controversies over the possible importance of HLA typing and the influence of blood transfusion illustrate the difficulties. In our study we did not consider a possible influence of $\sim \mathcal{N}$ timing of treatment on graft failure during the first three months $\frac{D}{O}$ after transplantation, though the good results in Belfast are in part related to the low incidence of failure in this period. The $N$ Belfast policy of morning-only dosing except during established $\mathrm{N}_{\mathrm{N}}$ rejection includes this first three-month period. Nottingham patients did not divide into two populations until after three months, preventing within-unit comparison. A policy in the first $\frac{\bar{D}}{\bar{D}}$ three months including evening administration of glucocorticoid $\stackrel{\oplus}{\rightarrow}$ could influence subsequent endogenous adrenocortical function, 0 even if morning-only treatment was prescribed later. It is pre-

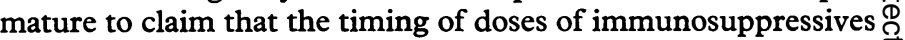
is very important, but this variable cannot be ignored when $\mathbb{D}$ considering immunosuppressive regimens. One communication reported that the courses of eight patients on morning-only dosing were no different from those of another eight takingo응 evening-only doses, ${ }^{28}$ but the numbers analysed were small and important differences might have been missed. An increasing $\overline{\overline{0}}$ amount of evidence is accruing from laboratory studies investi-? gating the timing of chemotherapy for malignant disease. ${ }^{29}$ We are unaware of similar laboratory studies on drugs given to prevent rejection after transplantation. More analyses of results 
obtained by other transplant units, with different policies on the timing of treatment, might also give useful information.

Those working in any specialty in which drugs are given, whether for immunosuppression or for other reasons, should consider whether better results might be obtained with less toxicity were more attention given to the frequency and timing of drug administration.

We are grateful to Mr R Blamey, Dr R P Burden, and the many other staff who helped in the care of these patients, and also to the colleagues in other units and to the patients who responded to the questionnaires. The research group is supported by grants from the Medical Research Council, the Nottingham and Nottinghamshire Kidney Fund, and Hoechst Pharmaceuticals Ltd.

Requests for reprints should be sent to MSK, Renal Unit, City Hospital, Nottingham NG5 1PB.

\section{References}

1 Di Raimondo VC, Forsham PH. Some clinical implications of the spontaneous diurnal variation in adrenal cortical secretory activity. $A m \mathcal{F}$ Med 1956;21:321-3.

${ }^{2}$ Smolensky MH. Rationale for circadian system phased glucocorticoid management. In: Scheving LE, Halberg F, Pauly JE, eds. Chronobiology. Tokyo: Igaku Shoin, 1974:199.

${ }^{3}$ Kowanko I, Readett D, Pownall R, Swannell A, Mahoney P, Knapp MS Nocturia, a side effect of single dose prednisolone and its dependance on the time of day of taking steroid. In: Reinberg A, Halberg F, eds. Chronopharmacology. Oxford: Pergamon Press, 1979:63.

4 Kabler TA, Knapp MS, Pownall R. The effects of corticosteroids given at various clock times on cell-mediated immunity to oxazolone. $\mathrm{Br} \mathfrak{F}$ Pharmacol 1978;64:427P.

${ }^{5}$ Pownall R, Knapp MS. A circadian study of corticosteroid suppression of delayed hypersensitivity. International fournal of Immunopharmacology $1980 ; 1: 293-8$.

${ }^{6}$ Harter JG, Reddy WJ, Thorn GW. Studies on an intermittent corticosteroid dosage regimen. $N$ Engl f Med 1963;269:591-6.

7 Scheving LE, Burns ER, Pauly JE, Halberg F, Haus E. Survival and cure of leukemic mice after circadian optimization of treatment with cyclophosphamide and 1 B D arabinofuranosylcytosine. Cancer Res 1977; 37:3648-55.

${ }^{8}$ McGeown MG. Immunosuppression for kidney transplantation. Lancet 1973 ;ii:310-2.

- Kumar P, Leech SH, Gonzalez FM, Kodlin D. Steroid treatment for routine immunosuppression in cadaver renal transplantation. A survey of hospitals. Clinical dialysis and transplant forum (abstracts). New York: National Kidney Foundation, 1978;8:27.

10 Kumar P, Leech SH, Gonzalez FM, Kodlin D. Antirejection treatment with steroids in cadaver renal transplantation. Dialysis and Transplantation 1978;7:1231-5.
${ }^{11}$ Naik RB, Abdeen H, English J, Chakraborty J, Slapak M, Lee HA. Prednisolone withdrawal after 2 years in renal transplant patients receiving only this form of immunosuppression. Transplant Proc 1979;11 : 39-44.

12 Naik RB, Chakraborty J, English J, Marks V, Slapak M, Lee HA. Serious renal transplant rejection and adrenal hypofunction after gradual withdrawal of prednisolone two years after transplantation. $\mathrm{Br} \mathrm{Med} \mathcal{f}$ $1980 ; 280: 1337-40$

${ }^{13}$ Knapp MS, Blamey R, Cove-Smith $R$, Heath $M$. Monitoring the function of renal transplants. Lancet $1977 ; \mathrm{ii}: 1183$.

14 Bell PRF, Calman KC, Wood RFM, Briggs JD, Paton AM, Macpherson SG. Reversal of acute clinical and experimental organ rejection using large doses of intravenous prednisolone. Lancet 1971 ;i:876-80.

15 UK Transplant Service. Annual report 1978/79. Bristol: UK Transplant Service, 1979:25.

${ }^{16}$ Brunner FP, Brynger H, Chantler $\mathrm{C}$, et al. Combined report on regular dialysis and transplantation in Europe. Proc Eur Dial Transplant Assoc $1979 ; 9: 1-70$

${ }^{17}$ McGeown MG, Longhridge WGG, Alexander JA, et al. One hundred kidney transplants in the Belfast City Hospital. Lancet $1977 ; \mathrm{ii}: 648-51$.

18 Chan L, French M, Beare J, Oliver DO, Morris PJ. Prospective trial of high dose versus low dose prednisolone in renal transplant patients. Transplant Proc 1980;12:323-4.

19 Mussche MM, Ringoir SMG, Lameire NN. High intravenous doses of methyl prednisolone for acute cadaveric renal allograft rejection. Nephron 1976;16:287-91.

${ }^{20}$ Gray D, Daar A, Shepherd H, Oliver DO, Morris PJ. Oral versus intravenous high-dose steroid treatment of renal allograft rejection. The big shot or not? Lancet 1978;i:117-8.

21 Knapp MS, Pownall R. Chronobiology, pharmacology and the immune system. International fournal of Immunopharmacology 1980;2:91-3.

${ }^{22}$ Cove-Smith JR, Kabler P, Pownall R, Knapp MS. Circadian variation in an immune response in man. $\mathrm{Br} M e d \mathcal{F} 1978 ; \mathrm{ii}: 253-4$.

${ }^{23}$ Kanpp MS, Cove-Smith JR, Dugdale R, Mackenzie N, Pownall R. Possible effect of time on renal allograft rejection, $\mathrm{Br}$ Med 7 1979;i:75-7.

24 Leisti S, Koskimies O, Rapola J, Hallman N, Perheentupa J, Vilska J. Association of postmedication hypocortisolism with early first relapse of idiopathic nephrotic syndrome. Lancet 1977; ii :795-6.

${ }^{25}$ Scheving LE, Von Mayersbach H, Pauly JE. An overview of chronopharmacology. Eur $\mathcal{f}$ Toxicol $1974 ; 7: 203-27$.

${ }^{26}$ Pownall R, Knapp MS. Circadian variations in immune responses. Clin Sci Mol Med 1978;54:447-9.

${ }^{27}$ Pownall R, Kabler PA, Knapp MS. The time of day of antigen encounter influences the magnitude of the immune response. Clin Exp Immunol $1979 ; 36: 347-54$.

${ }^{28}$ Chan MK, Varghese Z, Farrington K, Fernando ON, Moorhead JF. Is there a time factor in renal allograft rejection? $B r$ Med $\mathcal{F} 1979$; $:$ 748.

${ }^{29}$ Halberg F, Haus E, Cardoso SS, et al. Toward a chronotherapy of neoplasia: tolerance of treatment depends upon host rhythms. Experientia 1973;29:909-34.

(Accepted 9 October 1980)
ONE HUNDRED YEARS AGO Dr Hardwicke, the Central Middlesex Coroner, on Saturday, held a long inquiry, at the Buffalo's Head, Marylebone Road, as to the death, which we last week reported, of Mr Edward Amphlett, FRCS, aged 32, nephew of Baron Amphlett, and Assistant-Surgeon to Charing Cross Hospital. The death of the deceased occurred on Thursday morning, at his residence, 40 Weymouth Street, Portland Place. The evidence showed that on that morning, shortly before nine, he was found holding on to the balusters of the stairs, unable to proceed to his room, and Dr Murrell, residing next door, Dr Fox, of 14 Harley Street, and other physicians, were immediately called in. Death took place two hours afterwards. $\mathrm{Mr}$ Richard Holmden Amphlett, barrister, of 22 Upper Dorset Place, Dorset Square, and of the Temple, brother of deceased, said he was staying at Wychbold Hall, Droitwich, when the latter was taken ill. He was telegraphed for, but did not reach London until five hours after death had taken place. Deceased had suffered from asthma for years, and had been in the habit of taking chloral and morphia in considerable quantities. The books showed that deceased was in easy circumstances, having plenty of ready money and secured resources. His life was not insured, and no one benefited by the death. Esther Price, housemaid, confirmed previous witness as to deceased suffering from asthma; and Dr Murrell deposed that when he saw deceased he was sensible, but the pupils of his eyes were contracted. On charging deceased with having taken something in the way of chloral or morphia, he denied it. On being taken into a room, deceased became very drowsy, and the usual steps were taken to restore animation, including the application of galvanism; but all was in vain. He made a post mortem examination, and came to the conclusion that the death was from some overdose of medicine, probably morphia, or possibly morphia and chloral. The coroner asked if there were any letters that would throw light as to the state of mind of the deceased at the time. The brother replied that there were some letters, and it appeared that there had been also a disappointment in love. Several letters were here put in, and one from a lady to whom deceased had been engaged was read, in which she referred to having made the acquaintance of another gentleman. A copy of a letter from the deceased to the lady was also read, in which he stated that he had received his death-blow. A subsequent letter from the lady, from which it seemed that she had given him up, was also read, and the brother said he was sure the letters were enough to drive the deceased mad. The coroner, having summed up, left the jury to say whether the deceased had died by his own hand, or been accidentally poisoned; and, after a stormy discussion, lasting half an hour, the following verdict was returned: "The jury find that the deceased died from an overdose of narcotic poison, taken unconsciously whilst suffering from excitement; and, further, that such death was the result of misadventure." (British Medical fournal, 1880.) 